\title{
The Development in Leading e-Government Articles 2001-2010: Definitions, Perspectives, Scope, Research Philosophies, Methods and Recommendations: An Update of Heeks and Bailur
}

\author{
Christian Ø. Madsen ${ }^{1}$, Jesper Bull Berger ${ }^{2}$, and Mick Phythian ${ }^{3}$ \\ ${ }^{1}$ The IT University of Copenhagen, Copenhagen, Denmark \\ chrmaitu.dk \\ ${ }^{2}$ Roskilde University, Roskilde, Denmark \\ jbbergeraruc.dk \\ ${ }^{3}$ Centre for Computing \& Social Responsibility, \\ De Montfort University, Leicester, UK \\ mick.phythian@gmail.com
}

\begin{abstract}
This paper presents a study of the development in leading egovernment papers from 2001-2010. Inspired by a study by Heeks and Bailur, the analysis uses a different sampling method, adds new themes, and focuses on changes over time. Through an iterative process known as template analysis the five most cited papers from each year are analyzed according to themes such as perspectives on the impact and impact causes of e-government, methods used, underlying research philosophies and recommendations. Findings indicate that the papers are still somewhat optimistic regarding the impact of e-government, but no longer as technologically deterministic. Discussions of research philosophies start to appear, as do social constructionist studies, although most papers are still positivistic. There is an increase in the use of primary data, and some movement in focus from infrastructure and services towards citizens. There is little development in the discussions of generalization of results and recommendations offered.
\end{abstract}

Keywords: E-government, literature review, template analysis.

\section{Introduction}

Heeks and Bailur [22] reviewed e-government literature from 2001-2005 and state that narrow and poor research practice predominates [22, p. 260]. Yildiz [50] - from a literature review in the same period - finds e-government research to be of a 'deductive, outside-in approach' and states that these exploratory and descriptive studies 'do not tell us what is happening inside the black box of e-government'. According to Ndou [37, p. 3], 'one of the reasons why many e-government initiatives fail is related to the narrow definition and poor understanding of the e-government concept, processes and functions'. The need for a thorough understanding of e-government is thus perhaps even more salient now. 
Having stated a need for more in-depth knowledge of e-government the authors have conducted an e-government literature review from 2001-2010 as an update of Heeks and Bailur [22] to reveal how the e-government research field has changed. This paper examines the most cited papers' perceptions of what e-government is, what e-government is about and how e-government is performed. This is done by adopting the scales from Heeks and Bailur (e-government impact, impact causes, research philosophy, methods and recommendations) and adding the researchers' own scales of e-government content, which we believe has changed over time, at least within the most cited papers.

\section{Related Work}

The initial analysis for this literature review showed a major growth in papers using the term 'e-government' around 2001, which was also when two of the most cited works in the field were published; Layne and Lee's article on the development of egovernment stage models [32], and Jane Fountain's study of the interaction between IT and institutions [58]. These works differ in many of the aspects that we analyze. Layne and Lee's work is mostly conceptual and is technologically deterministic and optimistic [32]. It outlines a fixed path for e-government and the changes it will bring to organizations. Fountain presents three in-depth case studies and 'the technology enactment framework', a theory with a socio-technical standpoint that information technologies are changed by institutions, but also cause changes in these institutions as they are applied. Fountain argues that technologies are not always used the way the producers had intended [58]. This is a case often made outside the e-government field [72] but one that does not fit well with stage models or adoption models, where citizens' actions are typically limited to either adopting or rejecting the technology in question.

Previous literature reviews of e-government have focused on specific journals [22, 62] developing countries [13, 78], individual countries [73], or specific themes such as adoption [61, 75] or trust [51]. Others [50] did not base their review from a set sample of papers but instead focused on an in-depth discussion of certain themes. An alternative approach is found in bibliographical reviews which include several hundred papers but cover only certain areas available either from abstracts [65] or analyzing data from bibliographic databases [54].

None of these studies measure the papers in their literature reviews according to how frequently they have been cited. However, in one study [77], authors apply a network approach to literature review by aggregating results of studies that used the Technology Adoption Model (TAM) [57] to predict citizens' adoption of egovernment. This approach provides an overview of how frequently certain hypotheses were tested and validated. A similar meta-analysis has been conducted by Rana et al. [70].

Heeks and Bailur [22] analyzed eighty four articles published between 2001 and 2005 with 'e-government', 'e-governance' or 'digital government' in the title. The articles were chosen from three sources 'identified as the leading e-governmentspecific research outlets' [22] Government Information Quarterly, Information Polity 
and conference proceedings from European Conference on e-Government. They used template analysis [63] to analyze five main aspects of the articles 'whose selection was influenced but not determined by earlier research analyses in information systems and in public administration.' [22, p. 246]: Perspectives on impacts and impact causes, research philosophies, theory, methods, and recommendations.

Heeks and Bailur criticized the e-government field for being too optimistic and technologically deterministic, lacking theoretical basis and references to research philosophy, poor treatment of generalization, and lacking practical recommendations [22, p. 243]. Further, many authors were criticized for staying in their offices and thinking about how the development within e-government could, or worse, should take place, rather than actually conducting empirical studies [22, p. 257]. This led to articles suffering from 'naïve optimism'. Heeks and Bailur did find, however, that around half the authors criticized some of the positive statements about e-government, and a majority did not have an entirely technologically deterministic view on the impact causes of e-government [22, p. 249].

None of the literature reviews since Heeks and Bailur were based on in-depth analysis of the development over time across the e-government field. One of the primary purposes of this study was to see if the criticisms of Heeks and Bailur [22] had made an impact and whether there had been any development in the areas they mentioned. It was decided to use citation intensity as the primary selection criterion since the authors wanted to study papers from across the field that were frequently acknowledged through references. As a partly interpretative analysis was conducted, the researchers could not be sure that their interpretations were the same as Heeks and Bailur [22], it was therefore decided to include papers from both before and after the Heeks and Bailur study.

\section{Theory}

Template analysis (TA) [63] is a technique for analyzing texts using a template, which may contain initial themes for analysis but is developed through several iterations of reading and coding. King recommends that scholars start by coding a segment of the total texts and discuss areas of disagreement to develop the template. Through these iterations the development of the template becomes part of the analysis [63]. TA offers structure to an analytical process, but also flexibility in developing the template to suit the study. It has been applied for both quantitative and qualitative analysis by researchers with different epistemological positions [64].

Heeks and Bailur [22] based the perspectives notion on Rowe and Thomson [71]; so the authors returned to that source, where researchers' perspectives on the implications of IT are placed on a continuum from optimistic and technologically deterministic to pessimistic and socially deterministic.

The technological determinists regard technology as 'an autonomous force which compels society to adapt to it' [71, p. 20] and brings positive changes such as economic benefits and improved living conditions. Historical periods are classified by 
technology (Bronze Age, Information Age etc.) with technological revolutions in between. They typically study the long-term societal impact of technology.

Around the middle of the continuum are authors who regard technology as neutral, and study how political, cultural and other factors influence technology use and development. Rowe and Thomson [71] describe these authors using terms as 'sociotechnical', 'social shaping' and 'social constructionist'. Although different 'they all examine the way boundaries between the 'social' and 'technical' are negotiated, rather than accepting them as given.' [71, p. 24]. They emphasize peoples' and societies' choice in how technologies are used, and focus at the institutional level.

The social determinists regard technology as a social product, and often mention negative effects such as unemployment, pollution and surveillance. Instead of revolutions they believe in incremental change [49], and 'argue that technologies are found because they are sought; and are adopted, designed, released, applied and controlled by those trying to protect their own interests.' [71, p. 27].

Heeks [60] and Heeks and Bailur [22] developed Rowe and Thomson [71] separating it into two continua, thereby creating a two-dimensional field on which to place authors according to their value statements on the impact and impact causes of egovernment. The first dimension measures the potential perspectives on introducing e-government from purely optimistic to purely pessimistic; the other dimension measures the causes of the impact from technological determinism to social determinism. The midpoints consist of a neutral perspective with statements about both positive and negative impacts and a socio-technical perspective on impact causes with 'value statements about IT enabling or supporting outcomes that are also guided by human agency' [22, p. 247]. The researchers note that it is the potential impacts of introducing e-government that are measured, issues such as failed implementation or lack of adoption are not taken into account.

In their analysis of how the policymakers' perception of e-government has evolved Chadwick and May [10] present three models labeled as:

- Managerial - An offspring of e-commerce and New Public Management this model regards e-government as a tool to improve the 'business' of governance, to make it faster, cheaper and increase customer (citizen) satisfaction.

- Consultative - According to the consultative model governments can use IT to 'pull' information and opinions from citizens in order to improve policymaking. This is the first step towards improving democracy through the use of IT.

- Participatory - Chadwick and May [10] describe the participatory model as having 'utopian leanings' in its description of a 'cyber civil society' (p. 277) where citizens participate in democratic processes facilitated by IT.

\section{Method}

Citation intensity was chosen as the sampling criterion to study the papers with largest impact in the e-government field. It was drawn from Google Scholar using Publish or Perish. Employing Scholar included more sources, but limited triangulation due to unknown search algorithms, a similar search in Web of Science, for example, resulted 
in a narrower search base. Due to the Google search robot control constraints, the search was extended over several days.

The same starting year was used as Heeks and Bailur [22]. Analysis of citation intensity from 2012 (when the analysis was begun) showed that a paper had passed its inauguration period after two years, making 2010 the latest possible end year. Citation history analysis of the most cited papers from each year showed that they tended to stay in their position, due to the Matthew-effect [69]; papers keep getting cited because they have been cited previously or appear in certain journals [66].

The search criterion was that 'e-government' should be in the title. 'e-government' is the predominant notion (compared to 'e-governance', 'eGovernment' etc.). Due to resources available, only the five most cited papers every year were included. The sample is given in the 'Literature review sample references'.

The sample of fifty papers (see appendix B) included forty nine papers from 23 peer reviewed journals (nineteen from GIQ and seven from PAR). Thirty four would have appeared if Web of Science had been used. The papers that would not have appeared are generally those with the least amount of citations. All the papers with most and second most citations were included in the Web of Science sample.

The authors do not claim that citation intensity is equal to high quality research, only that it is an indicator for commonly acknowledged research, thus impact research. Scholars, however, do not necessarily reference all of their influences [67] and they also may cite research that they are not influenced by [66]. An extended scan of key words could validate this claim.

TA provided structure to the analysis and also encouraged the inclusion of new themes from the papers analyzed. From the coding of the first batch, it was discovered that the definition and type of e-government had evolved over time; hence these items were included. The definition type was taken from [10] and later collapsed into two values (managerial and consultative/participatory) due to unclear use in papers. A change in e-government application, level and practice emerged, thus we included these. [22] was included in the sample as one of the top five cited in 2007. It was discussed whether this paper which worked as a template for our analysis should be excluded for blocking the existence of a 'real' e-government research paper, but decided to stick to the method and keep the paper. A scale to distinguish between research on research and research per se was created. Some researchers employed very optimistic statements about the impact of e-government' [31], whilst other researchers were less optimistic, but more due to adoption and implementation issues than to egovernment impact as such [e.g. 46]. The authors introduced Heeks to this and he agreed that this could make the comparison difficult, on this basis a scale was created stating whether "not so optimistic' impact was due to adoption or implementation issues.

The coding was done in four iterations by two of the authors. Each iteration was finalized during whole-day meetings, where results were discussed and coding guidelines adjusted accordingly. The template was uploaded as an online questionnaire and adjusted after each iteration; adding scales after the first two iterations and deleting scales after the third and fourth. The first two batches (15 papers) were re-coded after the second iteration due to added scales and updated coding guidelines. 
The researchers strived to achieve data simplicity by using single-value coding; for eleven scales such as data collection methods multiple choice answers were necessary. The use of single choice coding had implications. A coding as 'neutral' on the optimism/pessimism scale can either stem from a paper having no value statements, [e.g. 20] or expressing both optimism and pessimism in the same paper [e.g. 3, p. 243]. The final template contained twenty three scales in total (see appendix A); fourteen scales from [22], (e-government perspectives, philosophy, method and recommendations), three that supported [22] and six new scales (e.g. e-government definition type, application and level).

The online template included space for coders' comments. After the first iteration it was discovered that these comments were not precise enough to recall reflections from reading the papers. It was then decided to add text citations to every coding. This led to shorter and more text focused arguments and increased discussion speeds significantly.

Initially the intention was to reach agreement on all scales through discussion, argument and reflection. An almost systematic deviation in coder differences on perspectives was revealed after the first iteration. One coder (with a natural science background) coded papers as more optimistic and technology deterministic than the other coder (with a humanities background). Reflecting on the statement from Heeks and Bailur that 'the same particular impact can be perceived by one stakeholder as positive while perceived by another stakeholder as negative' [22, p. 248] and after long discussions about perspectives, it was decided to accept a deviation of one point on the five point scale, and use the mean instead. For all papers, the scales for perspectives and research philosophy (considered the ones with highest degree of interpretivism), were discussed for agreement.

For the first two iterations (15 papers) coding was discussed and mutual agreement reached. For the last two iterations, the work was distributed and each coder elicited the common coding from the written argument and citations. After the third iteration there were 142 disagreements from coding of 15 papers (59\% intercoder reliability); after the fourth iteration, there were 70 disagreements from coding 20 papers $(85 \%$ intercoder reliability).

\section{$5 \quad$ Results}

This section describes the results of the analysis of the fifty most cited e-government papers in 2001-2010 by comparing the results to what Heeks and Bailur [22] found and by examining the evolution from the first five-year period to the next, if any.

\subsection{Perspectives on e-Government}

Impact from e-government (from optimistic to pessimistic) and impact causes (from technological determinism to social determinism) in the two five-year periods and average, are depicted in Figure 1. Papers were mostly optimistic during the whole period, with a tendency towards less optimism in the late period. A change is seen in 
impact causes from mostly technological determinism in 2001-2005 to a more balanced socio-technological view in 2006-2010, but with increased deviation.

No papers were found to be wholly pessimistic and only one was slightly pessimistic, the rest were coded neutral to optimistic. The statements ranged from full scale 'cyber-optimism' [12] where the impact is inevitable and unquestionable, e.g. that the second e-government stage 'is the beginning of the e-government as a revolutionary entity, changing the way people interact with their government.' [32, p. 128] to a slightly more reserved, but still positive outlook. The potential negative impact, e.g. privacy, security and the digital divide are treated more like barriers for adoption than regular drawbacks.

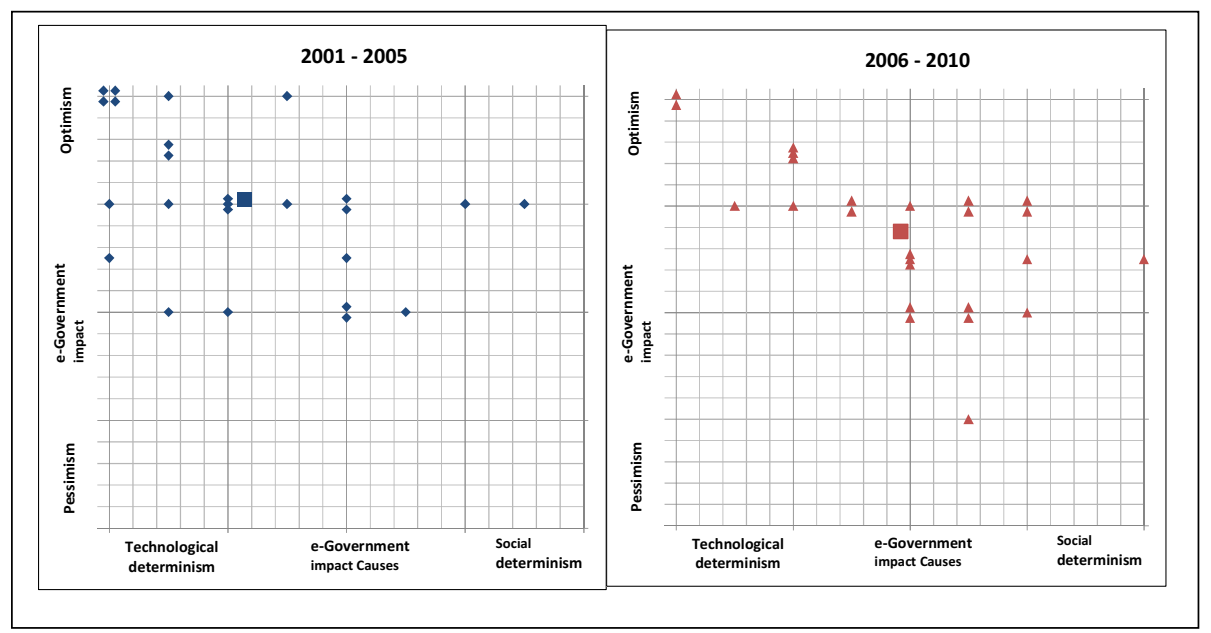

Fig. 1. Perspectives of impacts and impact causes of introducing e-government: left, 20012005; right 2006-2010

Coursey and Norris [12] criticize e-government stage models, Schuppan [40] is critical of e-government treated as a universal phenomenon that can easily be applied to developing countries, Heeks and Bailur [22] and Yildiz [50] criticize the research field. The digital divide hinders certain groups in society from achieving the benefits of e-government, resulting in 'long-lasting and widening economic gaps' [4, p. 117]. Coursey and Norris [12] state that e-government may 'simply reinforce existing power arrangements.' [12, p. 534]. The most critical group of papers concerns developing countries, e.g. increased corruption [40]. However, these papers also recognize positive impacts from e-government.

There was a notable development in impact causes from mostly technological determinism in 2001-2005 to socio-technical in 2006-2010. Where technology determinism rules, the Internet is the force that transforms the public sector [23, p. 434]. For the social determinists, it is use that shapes technology, which is regarded as an empty shell that carries the values of those that have chosen to have developed it, and those that use it in their everyday life. Moreover, the authors argue that these interests 
carried by technology are enacted by public sector organizations in their daily actions and routines [58], so that the outcome of e-Government reforms is shaped by the eGovernment policies' aims and goals, the technological characteristics shaped by these policies and the organizational practices which ultimately shape the actual outcomes of the reforms.' [11, p. 2].

Thirty two papers contain a definition of e-government. The increase in papers without definitions over time could be regarded as higher certainty of the central notion and increased maturity. Although not all papers have explicit definitions, there was an underlying understanding of e-government as 'the use of the Internet to deliver services and information to citizens and businesses [39, p. 52]. Sometimes egovernment plays an active transformational role, e.g. 'as a tool to achieve better government' [45, p. 288]. Actors are mostly defined as citizens (and businesses) although a more exhaustive range is sometimes used, e.g. 'citizens, business partners, employees, other agencies, and government' [32, p. 123].

Chadwick and May [10] saw a predominance of the managerial model over time and argue that 'the democratic potential of the Internet has been marginalized' Chadwick and May [10, p. 271]. The authors found signs of the managerial model in almost all papers; forty nine of fifty papers included 'efficiency' or 'costs' in the text. Half the papers still contained statements regarding e-government as citizens empowerment or enhanced democracy [15, p. 211].

\subsection{What Is the Scope?}

Several papers from the second period concern papers from the first. Three papers from 2006-2010 were meta-studies. Heeks and Bailur [22] and Yildiz [50] analyzed and criticized the research field, while Coursey and Norris [12] criticized the stage model approach [32] extended by Andersen and Henriksen [3] and synthesized by Lee [34].

Half the papers have government and four of ten had citizens as object of study. Only one paper investigates interaction with businesses [39]. Even though, many papers include government employees in the e-government definition, only one paper studies employees and government institutions [11].

Ten papers study e-government in developing countries [4, p. 4]. Another group of studies (eight papers), are concerned with the stage model view to e-government [32, $36,39,48,49]$, a synthesis of models [34] and criticism of stage models [3, 12]. Although some papers state that the study is about 'local government', 'government' is mostly treated generically with few characteristics except for size.

Forty eight of fifty papers include 'citizen' in the text. Factors that impact citizens' perception of e-government services (the demand side) are reported in one-fifth of the papers; trust [8] and risk [24] together with factors of the behavioral models constitute an almost archetypical form of statistical treatment of survey data to test hypotheses. Citizens are typically treated generically as well e.g. 'The term 'citizen' is used in this paper to indicate all constituents of e-Government, including resident aliens, businesses and other potential users of e-Government.' [46, p. 162], and with a few exceptions [42] include demographic and geographic variables and political affiliation. 
Services are an integral element of the e-government definition and it appears in the vast majority of the studies. The underlying assumption is that services are something that governments offer and that citizens can choose to use as stated by AlAwadhi and Morris [1] 'e-government services are highly voluntary'. This view makes the adoption process pivotal to e-government. Adoption is investigated using services as a general notion to be adopted by citizens [e.g. 1, 5, 24, 33, 42]. Other studies investigate specific services; tax filing $[5,8,26,46]$, automobile registration $[5,6,8]$ and use of e-mail communication [17, 49]. Studies deduce from either the general 'service' concept or from one or (in one case) two specific services to conclusions about e-government as such; e.g. Lean et al. [33] concludes from the general notion for services that 'perceived usefulness, perceived relative advantage and perceived image have significant positive relationship with citizens' intention toward using e-government services'. Carter and Bélanger [8] note that 'Clearly, the answers were influenced by the nature of the online services selected', recognizing the influence of the specific service that is investigated.

Examples of services are given: 'business license' [e.g. 32] or an exhaustive service taxonomy: payments, communications, licenses etc. [e.g. 29], however, only one definition of service has been found: 'Features were defined as 'services' if the entire transaction could occur online' [49]. Types of services are mainly derived by the egovernment stage model as information or transaction. Kumar et al. [31] find service quality crucial for adoption and presents five critical service quality factors.

The e-mail responsiveness study by West [49] is the only study of e-government services in use, the rest are studies of - at best - description of use, intention to use or purely conceptual.

Many of the early papers described e-government at a conceptual level; they would present e-government, discuss potential impacts, or predict its adoption. Only a few of the most recent papers $[11,17,40]$ contained in-depth analysis of actual use.

The political development in recent years has also created new areas for study. Egovernment services are now becoming mandatory in several countries. How does this affect citizens, both users and non-users?

Recognizing that e-government is multivariate and complex, it is surprising that little attempt to elaborate on, detail or dissect these often stated assumptions - or to even question the assumptions are seen, at least not within the most cited papers.

No in-depth studies of 'government', 'citizen' or 'service', either on a conceptual, theoretical or practical level are found. Scholars have argued that e-government applies to many domains and that no one model can be found [e.g. 56], yet no studies investigate or compare e-government in different domains. E-government is governed by legislation, politics and economy, yet, we see no studies of national government impact on how e-government is enacted in different public domains, institutions or levels. Organizational adoption can be tricky $[68,76]$; the role of top and middle managers are key $[55,59]$, however, none of the most cited papers deals with organizational issues within e-government. Acquisition- and tender processes, vendor relations, platforms or technology don't have the focus of the most cited papers. There are few studies that strive to encompass an overall model of e-government, e.g. an Enterprise Architecture view [14] or relevant internal and external technological, 
organizational, human themes etc. $[18,37]$. These studies provide a starting point for more detailed analysis.

Finally, none of the studies in the sample investigate the participatory, democratic or empowering element of e-government at all even though half of the papers refer to this in the definition of e-government or consider for the negative impact of egovernment.

\subsection{How Is e-Government Investigated?}

Heeks found that in only one of seven papers it was clear 'that the researchers had left their own offices and ventured out to do their research' [22, p. 257]. Only in five studies (one of ten) in the sample, researchers had left their offices to collect qualitative data from interviews, observations and focus groups.

As Heeks and Bailur [22] noted in 2007: 'This might, for example explain the absence from some research of the human, social, and political elements that more easily become apparent during direct contact with data subjects and settings' [22, p. 257]. We can repeat this seven years later; further, we can state as Heeks and Bailur [22]: 'those who had clearly left their office took a balanced sociotechnical perspective on e-government [22, p. 257].

The use of primary data increased over time. Twelve papers from 2001-2005 used primary data, compared to seventeen from 2006-2010. Further, five papers in the first period did not present any data compared to only one paper from the second period.

Four of the fifty papers contained longitudinal studies. Chadwick and May [10] studied e-government agendas across a decade, West [49] examined budget data from 1998-2000 and the development of content on US state and federal web sites from 2000-2001, Norris and Moon [38] analyzed results from two surveys on local governments' adoption of e-government, and Tolbert et al. [44] examined the development of e-government in US states from 2000-2004. Note that these studies covered the supply side of e-government. There were no longitudinal studies of e-government use by the demand side. There was a slight increase in studies that describe methods for data collection and analysis. Few papers, however, provide constructs for the research field to validate, criticize etc. Less than half the papers had discussions of validity and generalizability and there was no development in this over time.

Heeks and Bailur [22] found practical e-government recommendations in half their sample and 'three-quarters gave a few single sentence or, at best, single paragraph recommendations. Only four gave any specific guidance on how practitioners should take action' [22, p. 258]. In contrast, two thirds of the authors' sample gave recommendations; one third only provided recommendations of what, [34]. One third provided recommendations of how, [37]. Few studies contained comprehensive recommendations, other than Carter and Bélanger [8, p. 19].

In line with Heeks and Bailur (2007) we found that recommendations are seldom comprehensive. Further, we found fewer studies with specific how recommendations and more studies with what recommendations over time. Besides being sparse, recommendations point in many different directions (economy, website design, human skills etc.). No studies offer reflections on applying recommendations; i.e. political, strategic or tactical concerns, thus being of limited value for practitioners. 
Heeks and Bailur found no references to research philosophies, although they labeled them. In contrast, the authors' study found that the field has developed and polarized since. In line with their findings, there was no reference to research philosophy in the 2001-2005 sample. However, five papers from 2006-2010 did contain brief references to research philosophy. They were either labeled as 'murky middle' or social constructionist.

Almost three quarters of our sample were labeled positivist. Eight papers included definitions of independent and dependent variables and contained statistical testing of hypotheses. Five papers (one from 2003, four from 2006-2010) were labeled social constructionist, even if more than one quarter of the papers refer to Fountain, primarily 'The virtual state' [58], This may imply that researchers try to balance their work by citing a constructionist scholar. We find only one study, however, that states the specific impact of Fountain's work on the specific research [11].

The study shows the following regarding the most cited papers from 2001-2010:

- They remain positive about the impact of e-government, but have become less technologically deterministic. Many authors still attribute the impact of egovernment to technology alone

- The hypothesized benefits are mostly within the 'managerial model': reduced costs as a result of increased effectiveness and efficiency and better customer service

- The scope has changed from conceptual to a larger focus on actors e.g. citizens

- Government, service and citizen (the core of e-government) remain undefined

- Many e-government internal issues remain uninvestigated

- An increase in research maturity; more meta-studies, more primary data, more use of research methods, and more references to research philosophy over time

- A lack of descriptions of methods and generalizability of results. Very few studies use longitudinal methods, and there is little development in this area.

- Recommendations are sparse, more 'what to do' than 'how' to do.

- The underlying research philosophy in vast majority of studies remains positivistic.

\section{Implications}

Longitudinal studies can provide answers to questions and insights that are unattainable through cross-sectional studies [53]. Methods such as panel studies or time series [53] could be used to gain insight into citizens' or employees' actual and continued (or discontinued) use of e-government services, and what happens after adoption. Moreover, longitudinal studies can provide some directions to the path of egovernment. Transaction data has been recommended as suitable data for this purpose [3]. Another option could be to analyze the publicly available data from surveys of enterprises' and households' use of IT and e-government by the UN, OECD, and EU. Without longitudinal studies we are left with limited knowledge of the impact of and on e-government, and the underlying drivers.

The vast majority of papers in the sample represent an optimistic and positive view on e-government ranging from improved efficiency [29], reduced costs [37], faster services and enhanced quality [21], accountability and transparency [4], increased 
citizens' trust in government etc. The 'executive managerial model' [10] is by far the most predominant view; forty nine of the fifty papers include 'efficiency' or 'costs' in the text. Apart from the case studies from developing countries [e.g. 30, 37, 40], no paper offers any proof of e-government actually delivering the often claimed benefits.

In this study the researchers have analyzed the five most cited papers from each year from 2001 to 2010 with 'e-government' in the title. Would the picture have been different if ten papers had been selected? It is not known if the trend has changed since 2010. Has big data strengthened the focus towards specific domains or has social media introduced another view of the citizen? Both tendencies may be due to their novelty but may introduce more exploratory studies and move the focus away from positivism. A bias may have been introduced into the sample by only using 'egovernment' as search criterion, especially as 'e-governance' may have included more papers with the participatory/democratic scope. The authors consider that this study compares to Heeks and Bailur [22] despite the same sample collection method not being used. The first five years in the sample coincided with the predecessors and the same patterns were seen. The relatively small amount of papers in this study is a limitation, especially as it compares results over time, meaning there are only 25 papers in each group. The authors have tried to account for this limitation by comparing the results to other literature reviews, where possible, and by conducting an in-depth analysis with detailed examples from the papers studied.

\section{Conclusions}

The most cited papers on e-government have matured since the study by Heeks and Bailur [22]. There is more rigorous use of methods for data collection and analysis; more creation of primary data. Apart from this, we found pretty much the same patterns as they did, in some regards, we even saw a less diversified research field, including an overly optimistic e-government view based on strong technology determinism; a more positivistic approach and very few researchers that actually engaged in contact with data subjects and settings. E-government is agreed upon as governments delivering services to primary citizens through the internet. In this paper it is shown that the key notions in e-government, being governments, services or actors, all are treated rather vaguely, unsystematically and with no reasoned motivation, thus the e-government research scope seems unfocused. The most cited papers within egovernment research do not distinguish between types of government/public institutions or types/form of services and mostly ignores actors other than citizens, i.e. other public institutions or businesses; employees (that perform e-government) are entirely invisible; even citizens are treated evenly, no distinction between different segments of citizens' different needs and capabilities. This could explain why researchers' recommendations were consistently vague, unsystematic and unfocused.

Technology has matured, national e-government strategies and e-government initiatives are now part of the everyday political agenda, governments and institutions implement these initiatives and there are examples of states making government' digital services mandatory along with fiscal consequences, central government 
reducing state funding according to anticipated enhanced efficiency from implemented e-government initiatives. Cases where citizens have missed important information from public institutions because new e-government initiatives have emerged (a case in Denmark was settled on appeal and the public institution had to change egovernment practice and treat citizens' cases differently [74]) and cases, where civil servants express serious fatigue and stress due to performance pressure in combination with poorly aligned e-government technology and work practices that lead to low quality and errors in case handling, also have emerged [52].

The authors consider that there is a need for more balanced, qualitative and quantitative studies, more longitudinal studies and more contact with practice together with a further maturing of e-government research and not least a greater selfawareness from researchers of underlying perspectives and philosophy along with a more critical approach may move the research field to be better able to match the current e-government practice, thus ensuring the research fields' raison d'etre.

\section{References}

\section{Literature Review Sample}

1. AlAwadhi, S., Morris, A.: The Use of the UTAUT Model in the Adoption of Egovernment Services in Kuwait. In: 41st Hawaii International Conference on System Sciences (HICSS-41), Waikoloa, Big Island, Hawaii, p. 219 (1-11) (2008)

2. Almarabeh, T., AbuAli, A.: A general framework for e-government: definition maturity challenges, opportunities, and success. European Journal of Scientific Research 39(1), 2942 (2010)

3. Andersen, K.V., Henriksen, H.Z.: E-government maturity models: Extension of the Layne and Lee model. Government Information Quarterly 23(2), 236-248 (2006)

4. Basu, S.: E-Government and Developing Countries: An Overview. International Review of Law, Computers \& Technology 18(1), 109-132 (2004)

5. Bélanger, F., Carter, L.: Trust and risk in e-government adoption. The Journal of Strategic Information Systems 17(2), 165-176 (2008)

6. Bélanger, F., Carter, L.: The impact of the digital divide on e-government use. Communications of the ACM 52(4), 132-135 (2009)

7. Bertot, J.C., Jaeger, P.T., Grimes, J.M.: Using ICTs to create a culture of transparency: Egovernment and social media as openness and anti-corruption tools for societies. Government Information Quarterly 27(3), 264-271 (2010)

8. Carter, L., Bélanger, F.: The utilization of e-government services: citizen trust, innovation and acceptance factors *. Information Systems Journal 15(1), 5-25 (2005)

9. Carter, L., Weerakkody, V.: E-government adoption: A cultural comparison. Information Systems Frontiers 10(4), 473-482 (2008)

10. Chadwick, A., May, C.: Interaction between states and citizens in the age of the internet: "e-government" in the United States, Britain, and the European Union. Governance-an International Journal of Policy and Administration 16(2), 271-300 (2003)

11. Cordella, A., Iannacci, F.: Information systems in the public sector: The e-Government enactment framework. Journal of Strategic Information Systems 19(1), 52-66 (2010)

12. Coursey, D., Norris, F.: Models of E-Government: Are They Correct? An Empirical Assessment. Public Administration Review 68(3), 523-536 (2008) 
13. Dada, D.: The failure of e-government in developing countries: A literature review. The Electronic Journal of Information Systems in Developing Countries, 26 (2006)

14. Ebrahim, Z., Irani, Z.: E-government adoption: architecture and barriers. Business Process Management Journal 11(5), 589-611 (2005)

15. Evans, D., Yen, D.C.: E-Government: Evolving relationship of citizens and government, domestic, and international development. Government Information Quarterly 23(2), 207235 (2006)

16. Fang, Z.: E-government in digital era: concept, practice, and development. International Journal of the Computer, the Internet and Management 10(2), 1-22 (2002)

17. Gauld, R., Goldfinch, S., Horsburgh, S.: Do they want it? Do they use it? The 'DemandSide' of e-Government in Australia and New Zealand. Government Information Quarterly 27(2), 177-186 (2010)

18. Gil-Garcia, J.R., Pardo, T.A.: E-government success factors: Mapping practical tools to theoretical foundations. Government Information Quarterly 22(2), 187-216 (2005)

19. Gilbert, D., Balestrini, P., Littleboy, D.: Barriers and benefits in the adoption of egovernment. The International Journal of Public Sector Management 17(4/5), 286-301 (2004)

20. Guijarro, L.: Interoperability frameworks and enterprise architectures in e-government initiatives in Europe and the United States. Government Information Quarterly 24(1), 89101 (2007)

21. Gupta, M.P., Jana, D.: E-government evaluation: a framework and case study. Government Information Quarterly 20(4), 365-387 (2003)

22. Heeks, R., Bailur, S.: Analyzing e-government research: Perspectives, philosophies, theories, methods, and practice. Government Information Quarterly 24(2), 243-265 (2007)

23. Ho, A.T.K.: Reinventing local governments and the e-government initiative. Public Administration Review 62(4), 434-444 (2002)

24. Horst, M., Kuttschreuter, M., Gutteling, J.M.: Perceived usefulness, personal experiences, risk perception and trust as determinants of adoption of e-government services in The Netherlands. Computers in Human Behavior 23(4), 1838-1852 (2007)

25. Howard, M.: E-government across the globe: how will'e'change government. eGovernment 90, 80 (2001)

26. Hung, S.-Y., Chang, C.-M., Yu, T.-J.: Determinants of user acceptance of the eGovernment services: the case of online tax filing and payment system. Government Information Quarterly 23(1), 97-122 (2006)

27. Jaeger, P.T.: The endless wire: E-government as global phenomenon. Government Information Quarterly 20(4), 323-331 (2003)

28. Jaeger, P.T., Thompson, K.M.: E-government around the world: lessons, challenges, and future directions. Government Information Quarterly 20(4), 389-394 (2003)

29. Kaylor, C., Deshazo, R., Van Eck, D.: Gauging e-government: A report on implementing services among American cities. Government Information Quarterly 18(4), 293-307 (2001)

30. Kim, S., Kim, H.J., Lee, H.: An institutional analysis of an e-government system for anticorruption: The case of OPEN. Government Information Quarterly 26(1), 42-50 (2009)

31. Kumar, V., et al.: Factors for successful e-government adoption: a conceptual framework. Electronic Journal of e-Government 5(1), 63-76 (2007)

32. Layne, K., Lee, J.W.: Developing fully functional E-government: A four stage model. Government Information Quarterly 18(2), 122-136 (2001)

33. Lean, O.K., et al.: Factors influencing intention to use e-government services among citizens in Malaysia. International Journal of Information Management 29(6), 458-475 (2009) 
34. Lee, J.: 10 year retrospect on stage models of e-Government: A qualitative meta-synthesis. Government Information Quarterly 27(3), 220-230 (2010)

35. Mecella, M., Batini, C.: Enabling Italian e-government through a cooperative architecture. Computer 34(2), 40-+ (2001)

36. Moon, M.J.: The evolution of e-government among municipalities: Rhetoric or reality? Public Administration Review 62(4), 424-433 (2002)

37. Ndou, V.: E-government for developing countries: opportunities and chal-lenges. In: The Electronic Journal of Information Systems in Developing Countries, p. 18 (2004)

38. Norris, D.F., Moon, M.J.: Advancing E-Government at the Grassroots: Tortoise or Hare? Public Administration Review 65(1), 64-75 (2005)

39. Reddick, C.G.: A two-stage model of e-government growth: Theories and empirical evidence for U.S. cities. Government Information Quarterly 21(1), 51-64 (2004)

40. Schuppan, T.: E-Government in developing countries: Experiences from sub-Saharan Africa. Government Information Quarterly 26(1), 118-127 (2009)

41. Silcock, R.: What is e-Government? Parliamentary Affairs 54(1), 88-101 (2001)

42. Thomas, J.C., Streib, G.: The new face of government: Citizen-initiated contacts in the era of E-government. Journal of Public Administration Research and Theory 13(1), 83-102 (2003)

43. Tolbert, C.J., Mossberger, K.: The Effects of E-Government on Trust and Confidence in Government. Public Administration Review 66(3), 354-369 (2006)

44. Tolbert, C.J., Mossberger, K., McNeal, R.: Institutions, Policy Innovation, and EGovernment in the American States. Public Administration Review 68(3), 549-563 (2008)

45. Verdegem, P., Verleye, G.: User-centered E-Government in practice: A comprehensive model for measuring user satisfaction. Government Information Quarterly 26(3), 487-497 (2009)

46. Warkentin, M., et al.: Encouraging citizen adoption of e-government by building trust. Electronic Markets 12(3), 157-162 (2002)

47. Welch, E.W.: Linking Citizen Satisfaction with E-Government and Trust in Government. Journal of Public Administration Research and Theory 15(3), 371-391 (2005)

48. Wescott, C.G.: E - Government in the Asia - pacific region. Asian Journal of Political Science 9(2), 1-24 (2001)

49. West, D.M.: E-Government and the Transformation of Service Delivery and Citizen Attitudes. Public Administration Review 64(1), 15-27 (2004)

50. Yildiz, M.: E-government research: Reviewing the literature, limitations, and ways forward. Government Information Quarterly 24(3), 646-665 (2007)

\section{Other References}

51. Akkaya, C., Wolf, D., Krcmar, H.: The role of trust in e-government adoption: A literature review (2010)

52. Astrup, T.P., Flensburg, T., Olsen, M.: Heavy workload and slow IT frustrate civil servants. Politiken (2013) (in Danish)

53. Blaikie, N.W.H.: Designing social research: the logic of anticipation (2010)

54. Bolívar, M.P.R., Muñoz, L.A., Hernández, A.M.L.: Trends of e-Government Research. Contextualization and Research Opportunities. International Journal of Digital Accounting Research 10(1) (2010)

55. Braun, J., Ahlemann, F., Mohan, K.: Understanding Benefits Management Success: Results of a Field Study (2010) 
56. Carbo, T., Williams, J.G.: Models and Metrics for Evaluating Local Electronic Government Systems and Services. Electronic Journal of e-Government 2(2), 95-104 (2004)

57. Davis, F.D.: Perceived usefulness, perceived ease of use, and user acceptance of information technology. MIS Quarterly 13(3), 319-340 (1989)

58. Fountain, J.E.: Building the virtual state: information technology and institutional change, vol. xii, 251 p. Brookings Institution Press, Washington, D.C. (2001)

59. Gallivan, M.J.: Organizational adoption and assimilation of complex technological innovations: development and application of a new framework. ACM Sigmis Database 32(3), 5185 (2001)

60. Heeks, R.: Reinventing Government in the Information Age. International Practice in ITEnabled Public Sector Reform, p. 362. Routledge, New York (1999)

61. Hofmann, S., Räckers, M., Becker, J.: Identifying Factors of E-Government Acceptance A Literature Review. In: 33rd International Conference on Information Systems (ICIS 2012), Orlando, Florida, USA (2012)

62. Joseph, R.C.: A structured analysis of e-government studies: Trends and opportunities. Government Information Quarterly 30(4), 435-440 (2013)

63. King, N.: Template analysis (1998)

64. King, N.: Doing template analysis. Qualitatve Organizational Research: Core Methods and Current Challenges, pp. 426-450 (2012)

65. Kræmmergaard, P., Schlitcher, B.R.: A Comprehensive Literature Review of the EGovernment: Research Field over a Decade. In: tGov Workshop 2011 (tGOV 2011) (2011)

66. Larivière, V., Gingras, Y.: The impact factor's Matthew Effect: A natural experiment in bibliometrics. Journal of the American Society for Information Science and Technology 61(2), 424-427 (2010)

67. MacRoberts, M.H., MacRoberts, B.R.: Problems of citation analysis: A study of uncited and seldom - cited influences. Journal of the American Society for Information Science and Technology 61(1), 1-12 (2010)

68. Markus, M.L., et al.: Organizational and Institutional Arrangements for E-Government: A Preliminary Report on Contemporary IT Management Approaches in US State Governments. In: 46th Hawaii International Conference on System Sciences (HICSS-46). IEEE Computer Society, Wailea (2013)

69. Merton, R.K.: The Matthew effect in science. Science 159(3810), 56-63 (1968)

70. Rana, N.P., Dwivedi, Y.K., Williams, M.D.: A meta-analysis of existing research on citizen adoption of e-government. Information Systems Frontiers, 1-17 (2013)

71. Rowe, C., Thomson, J.: People and chips: the human implications of information technology (1996)

72. Silverstone, R., Hirsch, E., Morley, D.: Information and communication technologies and the moral economy of the household. Consuming Technologies: Media and Information in Domestic Spaces, 22 (1992)

73. Snead, J.T., Wright, E.: E-government research in the United States. Government Information Quarterly (2014)

74. The Council of Appeal on Health and Safety at Work. It was wrong to cancel child payment. Principle Decisions 2014 (Feburary 17, 2014) (cited March 29, 2014)

75. Titah, R., Barki, H.: E-government adoption and acceptance: a literature review. International Journal of Electronic Government Research 2(3), 23-57 (2006)

76. Tyre, M.J., Orlikowski, W.J.: Windows of opportunity: Temporal patterns of technological adaptation in organizations. Organization Science 5(1), 98-118 (1994) 
77. van de Wijngaert, L., Bouwman, H., Contractor, N.: A network approach toward literature review. Quality \& Quantity, 1-21 (2012)

78. Wahid, F.: The current state of research on eGovernment in developing countries: A literature review. In: Scholl, H.J., Janssen, M., Wimmer, M.A., Moe, C.E., Flak, L.S. (eds.) EGOV 2012. LNCS, vol. 7443, pp. 1-12. Springer, Heidelberg (2012)

\section{Appendix A: Template with Coding Scales}

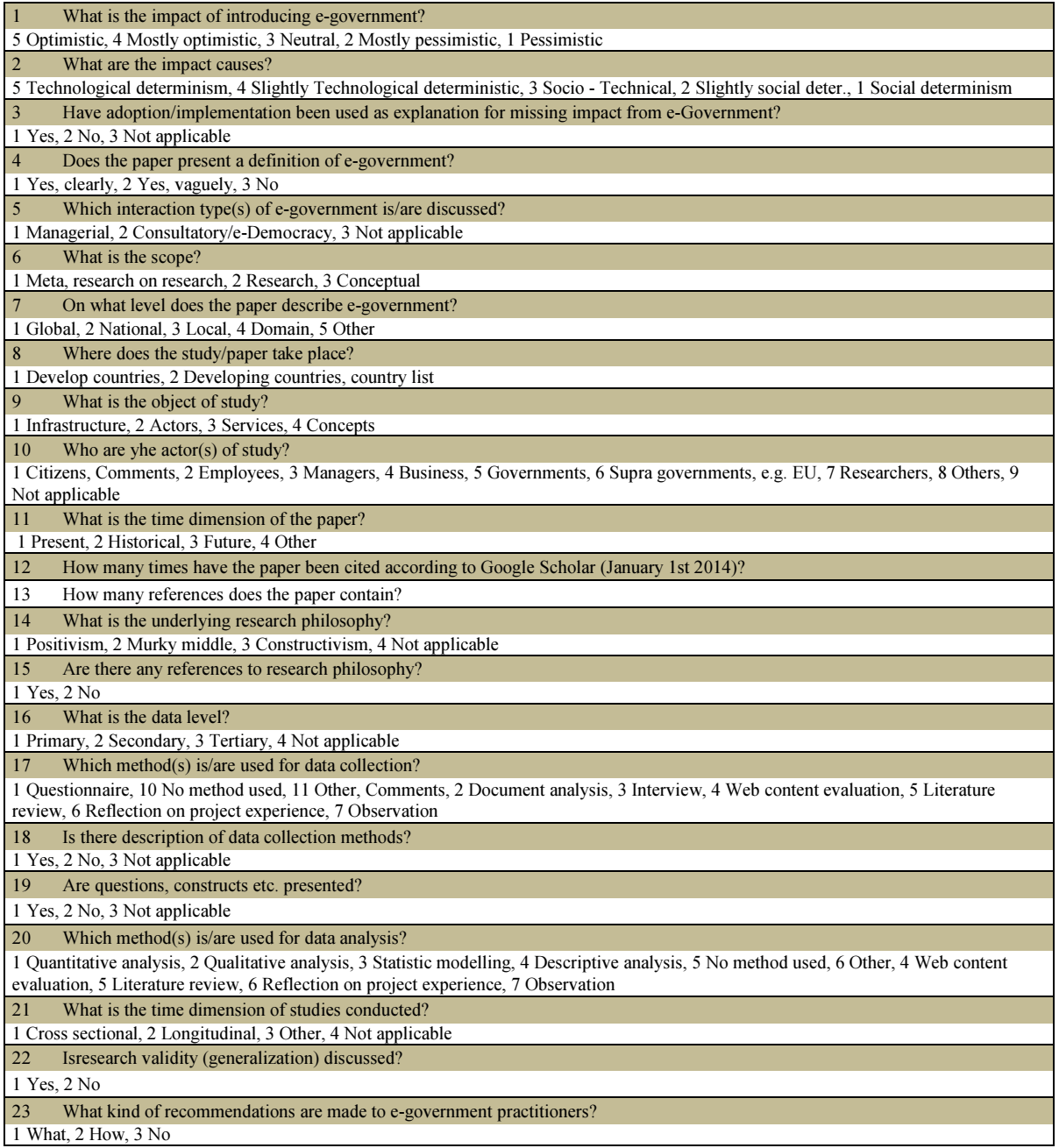




\section{Appendix B: Most Cited e-Government Research 2001-2010, Elected Scale Value}

\begin{tabular}{|c|c|c|c|c|c|c|c|c|c|c|c|c|c|c|c|c|}
\hline Year & Paper & 12 & 1 & 2 & 3 & 4 & 5 & 6 & 13 & 14 & 15 & 16 & 18 & 21 & 22 & 23 \\
\hline \multirow{3}{*}{2001} & Layne and Lee [32] & 1481 & 4 & 4 & 2 & 1 & 1 & 2 & 11 & 1 & 2 & 1 & 2 & 1 & 2 & 1 \\
\hline & Howard [25] & 121 & 5 & 5 & 2 & 1 & 1 & 2 & 0 & 1 & 2 & 3 & 1 & 1 & 2 & 1 \\
\hline & Wescott [48] & 116 & 4 & 3.5 & 2 & 1 & 1 & 2 & 74 & 1 & 2 & 4 & 2 & 1 & 1 & 1,2 \\
\hline \multirow[t]{3}{*}{2002} & Moon [36] & 1131 & 3 & 4 & 1 & 1 & 1 & 2 & 35 & 1 & 2 & 2 & 1 & 1 & 1 & 1 \\
\hline & Warkentin et al. [46] & 359 & 4.5 & 4.5 & 1 & 1 & 1 & 2 & 24 & 1 & 2 & 4 & 3 & 1 & 2 & 1,2 \\
\hline & Fang [16] & 295 & 5 & 5 & 2 & 1 & 1 & 2 & 21 & 1 & 2 & 4 & 2 & 1 & 2 & 1 \\
\hline \multirow[t]{5}{*}{2003} & Chadwick and May [10] & 440 & 4 & 1.5 & 2 & 1 & 1 & 2 & 73 & 3 & 2 & 1 & 2 & 2 & 2 & 3 \\
\hline & Thomas and Streib [42] & 337 & 3 & 3 & 2 & 3 & 1 & 2 & 19 & 1 & 2 & 1 & 1 & 1 & 1 & 1 \\
\hline & Gupta and Jana [21] & 294 & 4 & 2 & 1 & 3 & 1 & 2 & 31 & 2 & 2 & 1,3 & 1 & 1 & 2 & 1,2 \\
\hline & Jaeger and Thompson [28] & 260 & 3 & 3 & 2 & 3 & 1 & 1 & 22 & 2 & 2 & 4 & 3 & 1 & 2 & 1 \\
\hline & Jaeger [27] & 255 & 4 & 4 & 2 & 1 & 1 & 2 & 46 & 1 & 2 & 4 & 3 & 1 & 2 & 1 \\
\hline 2004 & Basu [4] & 222 & 4 & 4 & 2 & 1 & 1 & 2 & 41 & 1 & 2 & 3 & 2 & 1 & 2 & 1,2 \\
\hline \multirow[t]{5}{*}{2005} & Norris and Moon [38] & 344 & 3.5 & 5 & 2 & 1 & 1 & 2 & 55 & 1 & 2 & 2 & 1 & 2 & 1 & 3 \\
\hline & Carter and Bélanger [8] & 685 & 4 & 4.5 & 1 & 1 & 1 & 2 & 44 & 1 & 2 & 1 & 1 & 1 & 1 & 1,2 \\
\hline & Gil-Garcia and Pardo [18] & 333 & 5 & 5 & 2 & 1 & 1 & 2 & 84 & 2 & 2 & 1 & 1 & 1 & 1 & 1,2 \\
\hline & Welch [47] & 323 & 4 & 3 & 2 & 3 & 1 & 2 & 29 & 1 & 2 & 2 & 1 & 1 & 1 & 3 \\
\hline & Ebrahim and Irani [14] & 262 & 5 & 4.5 & 2 & 3 & 1 & 2 & 67 & 1 & 2 & 3 & 2 & 1 & 2 & 3 \\
\hline \multirow[t]{5}{*}{2006} & Tolbert and Mossberger [43] & 288 & 4.5 & 4 & 1 & 1 & 1 & 2 & 80 & 1 & 2 & 2 & 1 & 1 & 1 & 1 \\
\hline & Andersen and Henriksen [3] & 294 & 3 & 2.5 & 2 & 2 & 1 & 2 & 32 & 2 & 2 & 1 & 2 & 1 & 2 & 3 \\
\hline & Hung et al. [26] & 223 & 3.5 & 3 & 1 & 3 & 1 & 2 & 52 & 1 & 2 & 1,3 & 1 & 1 & 1 & 1,2 \\
\hline & Dada [13] & 158 & 2 & 2.5 & 2 & 1 & 1 & 2 & 28 & 3 & 1 & 3 & 2 & 4 & 2 & 1 \\
\hline & Evans and Yen [15] & 151 & 4 & 4.5 & 2 & 1 & 1 & 2 & 42 & 1 & 2 & 2,3 & 2 & 1 & 2 & 3 \\
\hline \multirow{2}{*}{2008} & Tolbert et al. [44] & 92 & 4 & 2 & 2 & 1 & 1 & 2 & 92 & 1 & 2 & $1,2,3$ & 1 & 2 & 1 & 3 \\
\hline & AlAwadhi and Morris [1] & 123 & 4 & 2 & 2 & 1 & 1 & 2 & 40 & 1 & 2 & 1 & 1 & 1 & 2 & 1 \\
\hline \multirow[t]{5}{*}{2009} & Verdegem and Verleye [45] & 153 & 4 & 4 & 1 & 1 & 1 & 2 & 92 & 1 & 2 & 1 & 1 & 1 & 1 & 1 \\
\hline & Schuppan [40] & 110 & 3 & 2 & 2 & 3 & 2 & 2 & 54 & 3 & 2 & 1 & 1 & 1 & 1 & 1 \\
\hline & Kim et al. [30] & 103 & 4 & 2.5 & 2 & 1 & 1 & 2 & 53 & 3 & 1 & 1 & 1 & 1 & 1 & 1 \\
\hline & Bélanger and Carter [6] & 72 & 4 & 3.5 & 2 & 3 & 1 & 2 & 12 & 1 & 2 & 1 & 1 & 1 & 1 & 1,2 \\
\hline & Lean et al. [33] & 89 & 4.5 & 4.5 & 2 & 1 & 1 & 2 & 79 & 1 & 2 & 1 & 1 & 1 & 2 & 1,2 \\
\hline \multirow[t]{5}{*}{2010} & Bertot et al. [7] & 231 & 3.5 & 3 & 2 & 3 & 1 & 2 & 111 & 2 & 2 & 4 & 2 & 1 & 2 & 1 \\
\hline & Gauld et al. [17] & 59 & 4 & 2.5 & 1 & 3 & 1 & 2 & 56 & 1 & 2 & 1 & 1 & 1 & 1 & 1 \\
\hline & Cordella and Iannacci [11] & 64 & 3.5 & 1 & 2 & 3 & 1 & 2 & 90 & 3 & 1 & 1 & 1 & 1 & 1 & 3 \\
\hline & Lee [34] & 50 & 4 & 3.5 & 2 & 1 & 1 & 2 & 39 & 1 & 2 & 3 & 1 & 1 & 2 & 1 \\
\hline & Almarabeh and AbuAli [2] & 53 & 5 & 5 & 2 & 1 & 1 & 2 & 18 & 1 & 2 & 3 & 2 & 1 & 2 & 1,2 \\
\hline
\end{tabular}

